\title{
Traces of Teaching Methods in a Language Class and the Relationship between Teacher's Intended Learning Outcomes and Students' Uptake
}

\author{
Zahra Mahmoudabadi ${ }^{1}$ \\ ${ }^{1}$ Department of Foreign Languages and Literature, Payame Noor University, Tehran, Iran \\ Correspondence: Zahra Mahmoudabadi, Department of Foreign Languages and Literature, Payame Noor \\ University, Tehran, Iran. Tel: 98-913-358-6227. E-mail: mahmoodabadi_z@yahoo.com
}

Received: April 16, 2017 Accepted: June 1, 2017 Online Published: June 2, 2017

doi: 10.5539/elt.v10n7p89 URL: http://doi.org/10.5539/elt.v10n7p89

\begin{abstract}
This study has two main objectives: first, to find traces of teaching methods in a language class and second, to study the relationship between intended learning outcomes and uptake, which is defined as what students claim to have learned. In order to identify the teaching method, after five sessions of observation, class activities and procedures were compared with typical techniques of previous methods. The findings showed that the teacher's method was an eclectic one which mostly followed CLT guidelines along with utilizing techniques from some other methods such as GTM, DM, and ALM. In the study of uptake, the students were given uptake charts (for vocabulary and grammar items) at the end of each session and based on their reports of uptaken items, it was concluded that uptake can reflect the intended learning outcomes and instructional procedures to a good extent, specifically for grammar items. Regarding idiosyncrasy of uptake, it was not found to be remarkably idiosyncratic, i.e. there was not much individual variation among learners' reported uptake.
\end{abstract}

Keywords: teaching methods; teachers intended learning; students' uptake

\section{Introduction}

Various language teaching methods have been developed and used over the past century, including the Grammar Translation Method, the Direct Method, the Audiolingual Method, Community Language Teaching, the Silent Way, Suggestopedia, Total Physical Response, and the Natural Approach. Furthermore, studies of uptake -what learners claim to have learned from a particular lesson - have focused on relationships between discourse features in classroom interaction and learners' perceptions of learning. Allwright's (1984) notion of uptake concerns the idea that language learning is a constructive process, in which contributions from participants in interactions lead to learning opportunities. One of the aims of studies of uptake is to distinguish between learning opportunities created by the teacher and those which may instead be attributed to student initiative and attention to discourse. Rather than expecting that learning outcomes are the products only of a well executed lesson plan, thus enabling teachers or researchers to predict which linguistic items will be uptaken by learners, it has been argued that individual learners will perceive what is important in different ways. Thus, uptake is concerned with relating learning outcomes to their immediate and potentially determining environment, through focusing on discoursal and interactive processes in the classroom.

Slimani has examined discourse in classroom interaction through evaluating the "quality of interaction which leads to learners' claims of uptake" (1992). Following Allwright, Slimani focused on learning which was the result of input that is jointly constructed, or what actually happened in an instructional setting, as opposed to (but not excluding) input which was planned beforehand and largely produced by the teacher. Uptake, according to Slimani, reflects both what teachers intend for students to learn, as well as aspects not previously anticipated by learners or teachers. In this view, learner autonomy, in terms of how students vary in attending to input in the classroom environment, plays an important role in determining how learning takes place. It is not clear as to what extent learners are aware of their own learning during instruction, but uptake may provide some evidence of the circumstances in which the input was noticed or attended to.

Slimani $(1989,1992)$ has reported on her study of uptake by thirteen Algerian students, low-intermediate to advanced beginners of English, enrolled in a six-month intensive ESL program. Students in this program met for a total of I4 hours a week; the classes were observed for two hours a week for six weeks. Learners were given uptake chart at the end of each of six observed classroom sessions and directed to provide as many details as 
possible on all points that they were able to recall from the day's lesson. Additional "uptake identification probes" were given to students approximately three hours after the first "uptake recall" charts, in order for them to distinguish items they listed which were learned in that particular lesson from those already partly known previously and from those which were available in the lesson but remained unclear to students. Both of the latter items were not further treated in the study, as the goal was to isolate the newly uptaken items and uncover sources in the interactive classroom work to explain the claims regarding learning or uptake. Claims of either previous partial knowledge or unclear knowledge from the immediate lesson alone were not considered relevant to the instances of learning claimed for the particular lesson. Additionally, Ruggiero (2008) comments that the term simply refers to the process involved in evaluating ideas. That is, by uptake and learning, we are in fact judging the precision of statements and also the soundness of the learning that leads to mastering the intended language item (p. 10). Moore and Parker (2009) also consider it as a tool to make acceptable learning. They further add that in uptake we use our potential talent in order to determine whether learning has happened effectively (p. 3).

The major findings by Slimani focused on the relationship between discourse features and the Iearners' uptaken items, in which it was found that uptaken items were those that were made topical and focused upon, overtly and largely by the teacher with an explicit use of metalanguage. However, only $44 \%$ of what was explicitly focused upon in the classroom discourse was claimed by learners to have been learned, and $35 \%$ was not mentioned or noticed (another $20 \%$ of topicalized items were claimed to be previously known). Slimani suggests that this indicates a picture of "syllabus as reality" as opposed to the "syllabus as plan" (Slimani 1992). In addition, while teacher talk made up the bulk of those linguistic items which were topicalized (158 items or $77.5 \%$ in classroom discourse, compared to 46 items or $22.5 \%$ by learners), learner topicalization produced proportionally more uptake. More precisely, only $49.4 \%$ of teacher topicalization was reported as uptake, while $79.9 \%$ of learner topicalization was reported as uptake. However, on the questionnaire eliciting learners' perceptions of their allocation of attention during the lessons, students ranked the input supplied by the teacher as most important, reflecting perhaps the sheer quantity of teacher topicalized items of uptake. Slimani suggests that based on the discourse features examined, however, "learners do, unknowingly, profit from their classmates' contributions" (Slimani, 1989).

Slimani also found that students' claims indicated that uptake was highly idiosyncratic, in that typically only a few learners at any one time "happened to take the information in" (1992). For example, nearly $75 \%$ of the total number of claims was reported by no more than three learners at a time, and $37 \%$ was reported by only one person at any one time. A much smaller number of claims (3.2\%) was simultaneously made by nine to eleven subjects. Thus, uptake in this study does not appear to reflect learning which is consistent with a prescribed syllabus. As Slimani notes, "many of the claimed items were not intended to be taught by the teacher but arose incidentally and became topics in discourse terms" (Slimani, 1992).

Given the above-mentioned points, two research questions are addressed in this study:

1). Does uptake reflect instructional procedures and intended learning outcomes (i.e., target grammar and vocabulary items)?

\section{2). Can uptake be considered idiosyncratic?}

The first question investigates relationships between uptake and intended learning outcomes. The second question addresses differences among learners in terms of how uptake is reported.

\section{Method}

\subsection{Participants of the Study}

In order to find traces of teaching methods, a language class in a private language institute has been observed for five sessions. The class met two times per week for 75 minutes. There were 17 elementary level students in this class. They had been classified in different classes based on a placement test. The teacher was experienced and had an MA degree in English language. Unfortunately, I was not allowed to audio-record the class. Therefore, the paper took some notes during the class sessions and immediately after the sessions, I tried to revise and complete my notes and add as much as I could remember. I was a non-participant observer. In the following section, I try to describe in detail two of the class sessions observed.

For the study of uptake, I observed the above-mentioned class for five sessions two of which were explained in detail in the study of teaching method. In order to determine the relation between the teacher's intended target items and the students' uptake, I asked the teacher to provide a list of target items for each session. These items included grammar and vocabulary items. Moreover, learners were given uptake chart at the end of each of five 
observed classroom sessions and directed to provide as many details as possible on all points that they were able to recall from the day's lesson.

In the analysis section, I compare the teacher's intended target items with the items claimed to be learned by the students.

\subsection{Description of Class Procedures}

\section{Session 1}

The teacher enters the classroom and greets the students briefly. She asks whether they have done what they were assigned to. The teacher suggests that first they start the new unit and then go back to the previous exercises. She asks them to open their books. She starts teaching unit 4. This exercise, called 'snapshot', introduces the theme of music and presents the vocabulary for various types of music popular in the United States. The teacher asks the students to close their books. She talks about music in Iran very briefly. Then, she asks some general questions about students' preferences in music. After that, she asks the students to open their books. While students are looking on that section, the teacher explains the new vocabulary. The teacher uses English most of the time but in some cases she also speaks a few words in Farsi when she feels that the students cannot understand some parts. It seems that most of the students have no knowledge of music types and it's difficult for them to understand the new words.

After the new words are explained, the students answer the questions following this section.

There is another part in which the students have to listen to different types of music and try to recognize them. The teacher ignores this part maybe because she believes that this activity is of no use to the students! or because the students are really unfamiliar with the types of music and this exercise can be confusing for them.

In the next part which is called 'word power' the teacher models the pronunciation of a list of words related to entertainment and the students repeat. Then she explains that they should classify the words based on the given categories. She gives them a few minutes to do the task. Then she elicits the students' answers. They answer voluntarily. The next section is a conversation which introduces 'yes/no questions' with' do'. The teacher asks the students to close the books. The teacher talks very briefly about the topic discussed in the conversation and sets the scene. Then she plays the audio program. Students listen. After it ends, the teacher asks some comprehension questions. Only a few students are able to give general answers. Then they open their books and the teacher presents the conversation line by line and explains the words which she thinks are unfamiliar to the students. Two students ask about the meaning of some other words for which the teacher gives synonyms or definitions. She asks the students to memorize the dialog for the next session so that they can recite it in pairs.

There is a second part for this section for which the teacher plays an audio program twice and the students are supposed to answer the related questions. Most of the students cannot understand this part. Apparently there is not enough time to go through it in detail. The next part which is called 'grammar focus', presents yes/no questions with do, reviews wh-questions with do and introduces object pronouns. The teacher uses the audio program to present the questions and the responses along with the object pronouns. Then she plays the audio program again, this time pausing it for students to repeat. After that, the teacher goes to the board and explains the grammar points on the board by giving some examples. There is an exercise which the students complete individually or in pairs.

The 'pronunciation' section follows the grammar focus. This part introduces intonation patterns used with yes/no and wh-questions with do. The teacher asks the students to close their books. She explains about what intonation is (here she uses a few sentences in Farsi). Then she asks them to open their books and plays the audio program while the students listen. After that, the teacher models the questions and the students repeat after her. She asks the students to listen to the audio program several times at home.

The last part covered in this session is an open-ended follow-up activity. The focus is on getting students to express themselves using their own information. The teacher spends a few minutes (less than what is expected) for a free discussion on entertainment. The students talk about the type of entertainment they like. At the end of the session the teacher asks reminds the students to memorize the dialog and work on the grammar points. Apparently, there is no time to work on the previously assigned exercises.

\section{Session 2}

Like the previous session, the teacher starts the class with a brief greeting. Then she asks for some volunteers to recite the conversation taught in the previous session. Two students come to the front and recite the conversation. The teacher helps them with some parts of it and asks some comprehension questions. The teacher calls for 
another pair and the same steps are repeated. Then the teacher starts teaching. The first part covered in this session is a 'listening' part. She asks the students to close their books and sets the scene for them. She plays the audio program while students listen. Then she asks the students to open their books and plays the audio program again. This time students listen and try to answer comprehension questions. The teacher pauses the player where necessary to give students time to write their answers. At the end, they check the answers.

The next part is a 'conversation' which is done through the same steps explained in session 1 . This conversation introduces making and accepting invitations; it also presents the grammatical structure verb+ to + verb and the modal would. The next section is 'grammar focus' which includes the same points mentioned in the conversation. This part is done exactly the same way as the previous session using audio program and explicit explanation. The next section taught in this session is another 'listening' part. In this part the students practice listening for specific information and making inferences. The teacher asks the students to close their books. She plays the audio program. When it is finished, she asks the students what they have understood. Then they open their books. The teacher plays the audio program again and has the students do the task.

The following part is 'writing'. In this part, the students practice writing creative invitations and responses to them. Some samples are given in the textbook. The teacher asks the students to do the writing for the next session. The last section covered in the second session is 'reading'. In the reading, the students read about three musicians from three different countries. They also practice scanning for ideas and facts.

First they have an initial discussion about the subject of the reading. Most of the students took part in the discussion, however, it seems that they had problems finding the words they meant. Then they open their books and three students read out the three parts of reading while the teacher explains the new vocabulary. The students complete the following chart which is meant to check the comprehension of the reading. After that, there is a pair work in which the students should answer and discuss some questions in pairs. At this time, the class ends. The teacher reminds the students that they will have a review of units 1-4 and they should do the related exercises at home.

\subsection{Data Analysis Procedure}

In order to identify the teaching method used in this class, we can compare the class activities and procedures with the typical techniques of the methods explained above. As Grammar Translation method (GTM) is concerned, techniques 2, 5 and 6 of this method are applied in this class, i.e. Reading Comprehension Questions, Deductive Application of Rule, and Fill-in-the-blanks techniques. Regarding Direct Method, the teacher utilized techniques 1, 2, 4, 5 1nd 7, i.e. Reading Aloud, Question and Answer Exercise, Conversation Practice, Fill-in-the-blank Exercise, and Paragraph Writing. Concerning Audio-Lingual Method (ALM), only techniques 1 and 3 are applied, i.e. Dialog Memorization and Repetition Drill. No technique is applied from community language learning (CLL), Silent Way, Suggestopedia and Total Physical Response (TPR).

To see whether Communicative Language Teaching (CLT) is utilized in the class, I refer to the section comparing CLT and ALM.

- With respect to the importance of form and meaning, CLT is applied as we cannot observe a lot of corrections for structure and form by the teacher, i.e. meaning is paramount.

- Regarding contextualization of items both CLT and ALM as items are taught both in context and in isolation.

- Comprehensible pronunciation is sought not native-speaker-like pronunciation. The teacher corrects the students' pronunciation only when they have serious problems, and this is one of the features of CLT.

- Judicious use of native language is accepted where feasible, i.e. the teacher uses native language where necessary.

- Translation is used where students need or benefit from it. This is another feature of CLT.

- Language is created by the individual often through trial and error, i.e. the teacher does not believe in error correction at all costs. This is also one feature of CLT.

- $\quad$ Based on CLT, students are expected to interact with other people, either in the flesh, through pair and group work, or in their writings and this is practiced in this class.

- According to CLT, intrinsic motivation will spring from an interest in what is being communicated by the language. In this class, the teacher tries to raise discussion topic in which the students seem to be interested.

As with the uptake study the classroom procedure is described as follows: 


\section{Session 1}

For session 1, the teacher provided a list of 16 vocabulary items and two grammar items.

Out of 16 vocabulary items, 8 items were related to musical styles. The students were supposed to learn not only the meaning of the words but also be able to explain what kind of style they are. The other 8 items were related to entertainment. In both parts, the new words were decontextualized, i.e. presented as a list.

The students reported 10 out of 16 items $(62 \%)$ to be uptaken. They remembered more words about entertainment. Musical styles seemed to be completely unfamiliar to most of the students.

Regarding grammar points, 15 out of 17 students (about 90\%) recalled both grammar points as being learned.

\section{Session 2}

The item list for the second session contained 8 vocabulary items and 1 grammar item.

Out of 8 vocabulary items, 3 (37\%) were reported as being uptaken. These items were part of a reading passage and were identified as the focus of attention by the teacher.

12 (about 70\%) students claimed to have learned the grammar point. They knew how to utilize the new structure but some said they couldn't understand exactly in what situations they should use these structures.

\section{Session 3}

9 vocabulary items and 1 grammar item were the intended target items for the third session.

Out of 9 items, 6 were related to family relations. There were more words related to family relations which were supposed to be known by the students. 7 out of $9(77 \%)$ vocabulary items were reported to be uptaken, mostly from the list related to family relations.

Almost all students (16 out of 17; nearly 95\%) claimed to have learned the grammar point which was present continuous tense. In class observation, it was noticeable that most of the students were able to make sentences using this structure and it could be implied that they had understood the concept underlying this structure.

\section{Session 4}

The item list for session four included 12 vocabulary items and one grammar item.

The vocabulary items for this session were all contextualized, i.e. they were part of a reading passage, a conversation, etc. Of these vocabulary items, $5(41 \%)$ were reported to be uptaken by the students.

The grammar point was claimed to have been learned by 14 students $(82 \%)$. This part was introducing the determiners to the students. The point to note is that these 14 students claimed that they have learned most of the determiners but not all of them.

\section{Session 5}

8 vocabulary items and 1 grammar points were the intended target items for the fifth session.

Out of 8 vocabulary items, $6(75 \%)$ were reported as uptaken by the students. Seven of these words were related to the types of sports and the verbs used with them. Most of these items were decontextualized and one target item had been used in a conversation.

In the grammar part, the teacher explained about the adverbs of frequency and their uses in sentences. Almost all students claimed that they had learned these adverbs but some confused their uses. On the whole, I consider 15 $(88 \%)$ students as learning the point.

\section{Results}

In the previous section, I calculated the percentage of uptaken vocabulary and grammar items separately for each session. Now, I consider the uptaken items as a whole.

\section{Vocabulary}

The average percentage for the uptaken vocabulary items was $55 \%$. That is, $55 \%$ of the words which were considered as the teacher's intended target items were claimed to be learned by the students. However, if we look more specifically at items uptaken in every session, we can see that the percentage of uptake was much higher for decontextualized vocabulary items compared to contextualized items. $71.3 \%$ of decontextualized items and $39 \%$ of contextualized items were reported to be uptaken. That is, those items which were focused upon individually, and not in context, were learned more. 


\section{Grammar}

As for the grammar items, the average percentage for the uptaken items was $85 \%$. This is a rather high percentage compared to that of vocabulary items, specially contextualized vocabulary items.

In Table 1, the percentages for uptaken vocabulary and grammar items are summarized.

Table 1. Vocabulary and grammar items percentage

\begin{tabular}{lllllll}
\hline Item Type & Session 1 & Session 2 & Session 3 & Session 4 & Session 5 & Average \\
\hline $\begin{array}{l}\text { Vocabulary } \\
\text { (contextualized) }\end{array}$ & & $37 \%$ & & $41 \%$ & & $39 \%$ \\
\hline $\begin{array}{l}\text { Vocabulary } \\
\text { (decontextualized) }\end{array}$ & $62 \%$ & & $77 \%$ & & $75 \%$ & $71.3 \%$ \\
\hline $\begin{array}{l}\text { Vocabulary } \\
\text { (both) }\end{array}$ & & & & & $55 \%$ \\
\hline Grammar & $90 \%$ & $70 \%$ & $95 \%$ & $82 \%$ & $88 \%$ & $85 \%$ \\
\hline
\end{tabular}

\section{Discussion}

Based on the comparison of typical techniques of different methods and the activities done in this class, we can conclude that the teacher did not follow one specific method in her teaching. Her teaching method mostly followed CLT guidelines. However, a good deal of techniques from other methods were also utilized, e.g., techniques from grammar translation method, direct method and audio-lingual method. Therefore, we can say that the teacher's teaching method is an eclectic one with the CLT approach dominating it which is a broad approach rather than a specific teaching methodology.

Since the overall percentage for vocabulary uptake is $55 \%$, the relationship between the intended learning outcome and vocabulary uptake is not that straightforward, i.e. we cannot answer this question as either 'yes' or 'no'. The students learned only half of what the teacher intended to teach them. However, if we consider the classification of vocabulary items in the study (contextualized and decontextualized), we can see that the percentage of uptake for decontextualized items is much higher than the non-contextualized ones. Therefore, we can conclude that the instructional procedures can influence the amount of uptake. That is, those vocabulary items which were focused upon individually, and not as a part of a context, were remembered more (71.3\%). This is a rather high relationship between the intended target items and the uptaken items. So, with respect to decontextualized vocabulary items, uptake can reflect the intended learning outcomes to a good extent.

Regarding grammar items, the answer to this question is 'yes'. As we saw the uptake percentage for grammar items is $85 \%$ which shows that most of the students learned the teacher's intended grammar items in every session. From another perspective, considering all five grammar items (each in one session) together, 12 out of 17 students (i.e. 70\%) had learned all five grammar items which is again an acceptable percentage for the uptake.

Generally, the findings of this study, for grammar items especially, suggest that evaluations based on teachers' plans may be an appropriate means for assessing students' Iearning.

Further, in this study, for both vocabulary and grammar items, uptake was not found to be as idiosyncratic as Slimani found in her studies. That is, the uptaken items were mostly identical among the students. There was not much individual variation among learners in what they reported as being uptaken.

On the whole, in the present study, findings indicate a rather strong association between the language reported as uptake by the learners and that of target items. That is, the majority of students reported uptake which directly reflected the instructional objectives. Therefore, the results emphasize the role of topicalization by the teacher supporting Slimani's (1992) study. It also goes without saying that like those who are native speakers, when second or foreign language learners master a piece of language their main goal is to comprehend its meaning that is they are trying to understand the uptake they receive. Traditionally, learning was regarded as a passive unconcious procedure and the learners were regarded as passive recipients, but, in fact, it is a process of interaction between the language and the learner. "The learner interacts with the uptake to create meaning as the mental processes interact with each other at different levels" (Barnett, 2009, p. 29). The learner is actually 
involved in an active and constructive process, building meaning from uptake. "Meaning does not exist in a context but in learners and the representations they build from uptake related to it" (Hass \& Flower, 2008, p. 167).

However, there was a stronger match between grammatical structures and instructional goals than that found for vocabulary. This may be due to the nature of structural and vocabulary items, i.e. vocabulary items require more individual practice to sink in compared to grammar items which can be learned easier and faster by means of instruction.

Moreover, the type of instruction can also influence uptake. As we saw, vocabulary items which were focused upon individually and explained about explicitly (similar to the technique the teacher used for grammar items) were reported more as being uptake.

\section{References}

Allwright, R. L. (1984a). The importance of interaction in Classroom Language Learning. Applied Linguistics, 5(2), 156-171. https://doi.org/10.1093/applin/5.2.156

Allwright, R. L. (1984b). Why don't learners learn what teachers teach? the interaction hypothesis. In D. M. Singleton, \& D. Little (Eds.). Language Learning in Formal and Informal Contexts (pp. 3-18). Dublin: Irish Association for Applied Linguistics.

Asher, J. (1977). Learning Another Language through Actions. The Complete Teacher's Guide Book (6th ed.). Los Gatos: Sky Oaks Productions, Inc.

Barnett, M. A. (2009). More than meets the eye: Foreign language learning: Theory and practice. Englewood Cliffs, New Jersey: Prentice Hall Regents.

Brown, H. D. (1994). Teaching by principles: An interactive approach to language pedagogy. Prentice Hall Regents.

Haas, C., \& Flower, L. (2008). Rhetorical reading strategies and the mastery of meaning. College Composition and Communication, 39(2), 167-183. https://doi.org/10.2307/358026

Krashen, S., \& Terrell, T.D. (1983). The natural approach. New York: Pergamon Publications.

Larsen-Freeman, D. (1986). Techniques and principles in language teaching. Oxford: Oxford University Press.

Moore, B. N., \& Parker, R. (2009). Effective learning through uptake. New York: McGraw-Hill.

Nunan, D. (1991). Language teaching methodology: A textbook for teachers. New York: Prentice-Hall.

Prator, C. H., \& Celce-Murcia, M. (1979). An outline of language teaching approaches. In M. Celce-Murcia, \& L. McIntosh (Ed.), Teaching English as a Second or Foreign Language. New York: Newbury House.

Richards, J. C., \& Rogers, T. S. (1986). Approaches and methods in language teaching: A description and analysis. Cambridge, UK: Cambridge University Press.

Ruggiero, V. R. (1998). Beyond feelings: A guide to uptake-based learning. CA: Mayfled.

Schmidt, R. (1995). Attention and awareness in foreign language learning (pp. 127-161). Honolulu: University of Hawaii Second Language Teaching and Curriculum Center.

Slimani, A. (1989). The Role of Topicalisation in Classroom Language Learning. System, 17, 223-234. https://doi.org/10.1016/0346-251X(89)90035-3

Slimani, A. (1992). Evaluation of Classroom Interaction. In J. C. Alderson, \& A. Beretta (Eds): Evaluating Second Language Education (pp 197-221). Cambridge, Cambridge University Press. https://doi.org/10.1017/CBO9781139524575.009

\section{Copyrights}

Copyright for this article is retained by the author(s), with first publication rights granted to the journal.

This is an open-access article distributed under the terms and conditions of the Creative Commons Attribution license (http://creativecommons.org/licenses/by/4.0/). 